\title{
A IMAGEM DA MODA E A CULTURA VISUAL COMO PROPOSIÇÕES PARA A DOCENCIA EM ARTES VISUAIS
}

Jociele Lampert ${ }^{1}$

(UDESC/CEART e ECA/USP)

\begin{abstract}
Resumo: O texto esboça uma parte de minha pesquisa de Doutorado em Artes Visuais pela ECA/USP. Partindo das relações de tensão entre a imagem da moda na cultura visual, assim como, o conteúdo de Artes Visuais e a formação docente (espeficamente o espaço do Estágio Supervisionado).

Paralavras-chave: Artes Visuais, Educação, Imagem da Moda, Cultura Visual.
\end{abstract}

Abstract: This text shows a part of my Doctoral Research in Visual Arts at ECA/USP. It starts from the relations of tension among the fashion image in visual culture, the content of Visual Arts and the teacher's formation (specifically the space of the Probation Period).

Key-words: Visual Arts, Education, Fashion Image, Visual Culture.

De acordo com Duncum, nunca antes na história da humanidade imagens foram tão centrais na criação de identidade ou no recolhimento e distribuição da informação - anteriormente a dominação estética dos produtos não era tão evidente e intensa quanto é hoje. A produção e distribuição de imagens tão óbvias e a tecnologia dessas imagens, facilmente manipuláveis, servem na contemporaneidade como referências pessoais para 0 individuo contemporâneo.

Parte-se das reflexões sobre a tese № 4 de Debord (1997, p. 14), onde se aponta que "o espetáculo não é um conjunto de imagens, mas uma relação social entre pessoas, mediada por imagens". A linguagem da sociedade do espetáculo, assim como, sua forma e seu conteúdo são construídos de sinais pertencentes ao modo de produção existente. Assim, a prática social que contém 0 espetáculo é também algo autônomo que permeia a espetacularização. $O$ espetáculo que inverte o real pode ser efetivamente um produto, ao mesmo tempo, que a realidade é materialmente invadida pela contemplação do espetáculo e retoma em si, a ordem espetacular da

\footnotetext{
${ }^{1}$ Professora efetiva do CEART/UDESC; Doutoranda em Artes Visuais pela ECA/USP; Mestre em Educação pela UFSM - RS (2005); Bacharel e Licenciada em Desenho e Plástica ambos pela UFSM - RS; Membro pesquisadora do GEPAEC/UFSM - Grupo de estudo e pesquisa em Arte, educação e Cultura e do Grupo de Pesquisa Arte e Educação/CEART/UDESC ambos diretório CNPq. jocielelampert@uol.com.br
} 
contemplação. Segundo Debord (1997), a alienação do espectador em favor do objeto se expressa da seguinte forma: quanto mais o homem contempla, menos ele vive, quanto mais aceita reconhecer-se nas imagens dominantes da necessidade, menos compreende sua própria existência e seu próprio desejo.

Tem-se na contemporaneidade o hiper-espetáculo. O espetáculo conforme apontava Debord acabou! O espetáculo tido onde o espectador era condicionado a contemplação passiva do outro, onde o espectador dependia do direcionamento do contemplado acabou. A contemplação continua, porém aproxima-se efetivamente de conceitos como a Alteridade - a contemplação de si mesmo num outro sujeito é o princípio alcançável de tempos hipercontemporâneos.

$\mathrm{Na}$ era da imersão digital e na era das celebridades, do 'direito ao ser famoso', o indivíduo contemporâneo pode 'imaginar-se' no lugar de seu objeto de admiração. Não há mais alteridade verdadeira, conforme aponta Silva (2007). O outro é 'eu' que deu certo graças à circunstancias. Silva (2007, p. 3) declina sobre a tese № 4 de Debord e aponta para:

\footnotetext{
1 - O imaginário não é um conjunto de imagens, mas sim uma relação social entre pessoas mediada por imagens. 2 - O simulacro não é um conjunto de imagens, mas uma relação social entre pessoas mediada por imagens.

3 - A socialidade não é um conjunto de imagens, mas uma relação social entre pessoas mediada por imagens.
}

Assim, para Debord o espetáculo estaria configurado pela imagem do mundo. No hiper-espetáculo, a imagem de si mesmo é a forma espetacularizada e descontrolada de ver-se no mundo e reconhecer-se no outro. Se existia antes uma ilusão de controle ou disciplina, isto se finda na era do hiper-espetáculo. Quanto ao papel da mídia, em veículos de comunicação de massa, entende-se que esta não 'diz' o que o indivíduo deve falar, nem sobre o que falar, mas sim, em torno do que deveria o sujeito falar. Para Silva (2007), a imagem torna-se um 'totem vazio de conteúdo e cheio de atrações' para as práticas sociais.

Desta forma, refletindo sobre a virada cultural na contemporaneidade, que impulsionou mudanças de paradigma do conhecimento sobre as práticas sociais e culturais, pressupondo uma expansão conceitual, tem-se o estruturalismo, onde os significados de uma cultura são produzidos por práticas que funcionam como sistemas de significação. A arte como linguagem 
aproxima a tessitura do texto visual, síntese visual, ou semântica da imagem. Linguagem e imagem foram objetos de estudo da Escola de Frankfurt, criando eixos epistemológicos contraditórios e dúbios sobre os conceitos de imagens da arte como foco de referência para análises e avaliações de práticas e experiências culturais. Conforme Martins (2007, p. 21), "oferece-se ao público a possibilidade de conjugar percepção crítica e prazer estético, contrariando os cânones de uma prática erudita e desmistificando o rito da contemplação como fruição individualizada”. Essas transformações ampliam as possibilidades de relação e diálogo dos indivíduos com a arte, com a imagem e com a cultura visual, pois a difusão da imagem como representação visual subverte a distinção entre arte erudita e arte popular, sendo que o espectador passivo do espetáculo pode torna-se um produtor de novos valores sociais e linguagens culturais.

Neste contexto, as teorias do pós-estruturalismo posicionam a cultural visual, como "uma concepção inclusiva que torna possível a incorporação de todas as formas de arte e design ou fenômenos visuais relacionados com o corpo e tradicionalmente ignorados", conforme aponta Guasch (2003, p.14). Assim, a cultura visual aponta para visualidades, não apenas pelo valor estético, mas sim porque busca compreender o papel social da imagem na vida cultural do indivíduo.

A partir dos anos 80, a teoria social crítica passou a formar parte do discurso da Educação e da Arte, alimentando o crescimento de perspectivas sociais em campo, o que levou a concepção. Segundo teóricos (MIRZOEFF (1998), MITCHELL (1995)), a cultura visual ainda é uma idéia em formação, por tratar-se de um campo ou abordagem aberta e não disciplinas, mas sim, com características poli - disciplinar que constitui abordagens trans-metodológicas perpassando a antropologia visual, a sociologia e os estudos culturais, estendendo-se até as Artes Visuais. A cultura visual representa visualidades específicas que se verificam por meio de visibilidades. A cultura visual pode ser usada para cobrir a memória visual, ou ainda, ser entendida como uma manifestação sobre a produção de objetos visuais produzidos pelo homem (conforme FREEDMAN (2006)).

Para Mirzoeff (1998), o mundo contemporâneo é hiper visual. Vive-se em um ambiente cultural modificado, que inclui simbioses entre a tecnologia, a 
formação social e os arranjos econômicos. Deste modo, observar novas visualidades e buscar compreender a visibilidade é tarefa do ensino de Artes Visuais, ou seja, educar em imagens e sobre imagens. Seguindo este pensamento a cultura visual pode ser:

Eventos visuais nos quais informação, sentido/significado ou prazer é procurado pelo consumidor numa interface com a tecnologia visual (que é) qualquer forma de aparato projetado para ambos serem olhados ou melhorarem a visão natural, de pintura a óleo á televisão e a Internet $(1998$, p. 3)

Como um campo, a cultura visual, é geralmente informada do ponto de vista de que artefatos visuais e sua percepção, são parecidos tendo um limite contextual, isto é, são tangenciados mas, podem ser estudados isoladamente, o que pressupõe perceber e refletir sobre a experiência visual de cada sujeito levando em conta seus repertórios, crenças e valores. As imagens podem ser percebidas em contextos de processos e pressões sociais amplas, entre linhas/fronteiras distorcidas entre o estudo das imagens e da sociologia, ou antropologia visual como eixos flutuantes. A cultura visual pode ser uma tática para estudar genealogias, definições e funções da estética cotidiana na contemporaneidade.

O que deverá interessar aos professores de Artes Visuais são os artefatos visuais (não somente aqueles pertinentes ao conteúdo de Artes Visuais, mas assim como, os artefatos que constituem atitudes, crenças e valores presentes no cotidiano do homem contemporâneo). Conforme Duncum (1997, p. 20):

O termo visual sugere que nós estamos preocupados substancialmente com artefatos visuais. Artefatos geralmente envolvem outros códigos que não os visuais e comprometem outros modos sensoriais que não a visão, mas nós estamos interessados em artefatos para a extensão à qual, ou quando, nós inferimos que eles tem um significado que é substancialmente visual. Em segundo lugar, o termo cultural sugere um interesse que vai além dos artefatos em si. Isto sugere um interesse nas condições sociais dos artefatos que têm existência, incluindo sua produção, distribuição e uso. Imagens são vistas em sua riqueza contextual, como parte de um discurso social em andamento que envolve sua influência na vida social.

A cultura visual poderá ainda se tida como um rizoma, pois propõe princípios de multiplicidades, rupturas e conexões infindáveis e em variadas direções. Assim, Duncum apud Pearson (1997, p.71), diz que "o objeto de interesse da arte-educação é constituído por um campo social no qual imagens são produzidas, distribuídas e usadas", neste ponto de vista, o ensino de arte 
assume a forma de investigação para as práticas sociais, as quais constituem o campo da visualidade. Assim, o que o ensino de Artes Visuais necessita de uma mudança de paradigma que reconheça a hegemonia da mídia de massa e se aproxime da mídia com as ferramentas conceituais apropriadas. Conforme Duncum (1997), tudo aquilo que agora existe é representação, com habilidade de seduzir, oprimir, intoxicar e entregar a um estado de hiper-realidade. A vida diária tem se tornado estetizada, embrulhada numa estética de superfície, onde a discriminação tem sido substituída pela 'folia' - entende-se também, a mudança paradigmática entre ser e ter e ter para parecer.

A razão de estudar a cultura visual, ou ter um dos eixos do ensino de Artes Visuais centrado na cultura visual é que esta poderia prover os estudantes com um conjunto de ferramentas críticas para a investigação da visualidade humana e não 'transmitir' informações ou valores, conforme aponta Mitchell (1995). Os estudantes vivenciam mundos digitais/virtuais e tecem redes sociais que se configuram em correntes de proliferação e imagens onde identificam-se por meio de subjetividades a construção de identidades. O local de significação dessas imagens deve ser percebido como um local de intersecções.

Considerando este contexto, como os professores de Artes Visuais deveriam responder a este tempo contemporâneo? Talvez entender que é preciso mudar e parar de defender-se em um escudo modernista e tradicional que pressupunha uma formatação 'estanque' de ensino (onde o professor ensinava e o estudante aprendia verdades absolutas); entender que é necessário perceber o contexto onde o estudante está inserido além dos muros da escola, inclui-se aqui a necessidade da percepção para as tendências digitais/virtuais; reconhecer a relevância da comunicação de massa, dos veículos midiáticos e planejar e integrar essas novas formas estéticas ao currículo proposto.

Garoian \& Gaudelius (2008), enfatizam a cultura visual como uma "pedagogia do espetáculo", na qual imagens ensinam 'o que' e 'como' pensar propondo interação social. Estes autores apontam a necessidade dos professores compreenderem criticamente expressões institucionalizadas e corporativas de subjetividades, bem como, a necessidade de entender expressões pessoais de subjetividade através da produção artística - é 
necessário que haja sobre o espetáculo da cultura visual um olhar crítico e somente com práticas pedagógicas contemporâneas e currículos atualizados (criticamente) isto será possível. Conforme Mirzoeff (2003, p. 53):

\begin{abstract}
Em uma sociedade do espetáculo, os indivíduos deslumbrados pelo espetáculo surgem de uma existência passiva dentro da cultura visual do consumo de massa, aspirando somente adquirir uma maior qualidade dos produtos. Em uma sociedade espetacular se convence pela imagem mais do que pelo objeto.
\end{abstract}

Desta forma, imagens podem assumir formas ideológicas, pois influenciam modos de interação entre os indivíduos. Uma imagem não é simples um negativo ou positivo, mas, melhor que isto, é um produto de relações sociais que produzem efeitos contraditórios. Seguindo o pensamento de Garoian \& Gaudelius (2008), a pedagogia do espetáculo da cultura visual pode ser vista partindo dos seguintes eixos: primeiro, como uma forma onipresente de representação que constitui os objetivos pedagógicos da cultura de massa mediada pelo capitalismo corporativo para manufaturar desejos e escolhas; segundo, pode ser uma forma democrática de prática que possibilita um exame crítico dos códigos e ideologias da cultura visual para resistir à injustiça social.

Dado o apelo de massa, o poder da cultura visual do espetáculo atua em seu funcionamento pedagógico, pois se torna ornamento da massa. Assim, a cultura visual pressupõe hipérboles visuais que configuram discursos críticos fracionados em múltiplos lugares (e disciplinas). A cultura visual no ensino de arte pode ser vista como um processo de produção de significado intertextual (situando-se em textos dentro de um capo com outros textos). Espera-se que o professor de Artes Visuais parta seu planejamento de questões que poderão configurar identidades/ subjetividades em contextos oriundos de imagens e assim, definir meta-narrativa visuais como discursos em que o poder emite através da linguagem estendendo a reflexão crítica até o estudante. A crítica ajuda não somente a realizar juízos e reflexões sobre suas próprias posições, mas sim, dar-se conta do dimensionamento da área de conhecimento e do mundo que se vive.

Para Freedman (2006), um importante aspecto educativo da cultura visual é seu efeito sobre a identidade, tanto no que diz respeito a criação como a observação, como questões de maior importância para a educação. A 
educação é um processo de formação de identidade porque troca-se à medida que se apreende.

As Artes Visuais torna-se de fundamental relevância para a transformação cultural do discurso político, considerando a interação social e as formas de tessituras identitárias que caracterizam uma condição contemporânea, segundo Jameson $(1984,1991)$. Isto pode manifestar-se de fato por meio de imbricações culturais interpessoais, ou em encontros sociais, institucionais incluindo aqui as práticas educativas. È papel da escola gerar novas problemáticas e tendências aos sistemas de produção: tencionar acesso, gestar a produção, divulgação e legitimação do conhecimento. Somente assim, será possível impulsionar formas de aprendizagens autônomas e colaborativas centrando na indagação e ou questionamento em dinâmicas contextuais e transdisciplinares. O que se busca é compreender a forma como se constitui o efeito de sentido ou como se dá significado as coisas.

E qual seria o campo intelectual do ensino de Artes visuais? Seria um âmbito do pensamento dentro do qual existe a prática que tem a ver com 0 quê, por quê e como chegamos a ter conhecimento sobre a cultura visual. A cultura visual é um campo de intersecção entre a Educação e a Arte e como as pessoas pensam sobre Arte. Assim, entende-se a cultura visual como um possível ponto de articulação na formação docente em Artes Visuais.

Uma das maiores dificuldades observadas entre alunos do curso de formação inicial em Artes Plásticas é que os acadêmicos não possuem uma postura como professor pesquisador e assim, pesquisar, estudar e definir a temática que deverá ser desenvolvida no estágio torna-se um trabalho exaustivo e muitas vezes caótico. Costumeiramente, o Estágio Supervisionado não é visto ou tido como pesquisa, ficando em meio a formulários, projetos isolados e relatórios ou artigos vagos, perdidos em relatos de experiências sem reflexões ou direcionamentos teóricos. Penso que refletir sobre a imagem da moda (como um sistema estético) em consonância com o conteúdo de Arte, seria uma articulação possível ao Ensino de Arte (tanto na Escola quanto em bancos universitários). Usada como temática geradora ou estratégia para abordar o conteúdo de Artes Visuais, a imagem da moda torna-se um viés possível para a formação de professores nesta investigação. 
A tessitura sobre a sociedade do espetáculo, ou algo que estaria além do espetáculo centra-se nas relações sociais compreendidas pela imagem da moda em meio a um contexto social da formação docente, ou seja, busco refletir como o professor em formação inicial é afetado pela imagem da moda ou pela sociedade do espetáculo e como ele abordaria a temática da moda interrelacionada ao conteúdo de Artes Visuais se o levasse para a Escola.

A moda é uma linguagem que organiza e articula sistemas de expressão: a indumentária/roupa e o corpo como suporte. Assim, podemos buscar entender significados sociais e culturais apresentados em atitudes, crenças e valores. A imagem da moda centra-se nesta pesquisa imbricada a discussão sobre o campo da Cultura que tem caráter interdisciplinar por apresentar diferentes e múltiplas camadas de significados culturais. Estas camadas são conjuntos de valores, de crenças e significados que nossos alunos muitas vezes utilizam para dar sentido ao mundo em que vivem. Articular a educação à cultura visual pode ser a conexão para religar o mundo social e o simbólico das representações e assim, refletir criticamente sobre compreensão da visualidade contemporânea que permeia o cotidiano.

A reflexão sobre a visualidade contemporânea deverá ser permeada pelas condições de visibilidade, assim educar em imagem e sobre imagens, possibilita a percepção da experiência visual individual (no caso da pesquisa do professor em formação inicial). A cultura visual relaciona-se com formas culturais, investigadas pela identidade/subjetividade, conceitos de cultura, de diferença e de representação social do indivíduo. Especificamente, outros objetivos estão sendo buscados nesse estudo: investigar a possibilidade do uso estratégico da linguagem da moda nas aulas de Artes Visuais na disciplina de Estágio Supervisionado no curso de Licenciatura em Artes Plásticas CEART/UDESC; pesquisar como se inter-relacionam a Imagem da Moda, Artes Visuais e Educação na contemporaneidade em relação a cultura visual; impulsionar formas de ensino e aprendizagem (autônomas e colaborativas), situando o conhecimento produzido pelo professor em formação inicial em uma dinâmica contextual e transdisciplinar.

Assim, se a moda faz parte da sociedade do espetáculo, bem como, da cultura visual poderá ser passível de ser articulada com o conteúdo no Ensino da Arte. Desta forma, poderá ser pensada como elemento articulador na prática 
docente. Como problemática da pesquisa centram-se os seguintes questionamentos: de que maneira o professor em formação inicial de Artes Visuais é afetado pela imagem da moda e pela sociedade do espetáculo? E como o professor em formação inicial pode articular a cultura visual especificamente imagem da moda, com o conteúdo de Artes Visuais na escola?

Conforme Tripp (2005) e Thiollent (2004), a pesquisa-ação aplica-se quando o pesquisador busca efetuar transformações em sua própria prática. Assim, esta forma de pesquisa deverá ser: inovadora, contínua, pró-ativa, estrategicamente participativa, intervencionista, problematizada, deliberadamente documentada, compreendida e disseminada no seu contexto social. A reflexão é essencial ao processo da pesquisa-ação, sendo uma reflexão participativa e colaborativa envolvendo criticidade do pesquisador e sujeitos participantes da pesquisa. "A pesquisa-ação é participativa na medida em que inclui todos os que, de um modo ou outro, estão envolvidos nela e é colaborativa em seu modo de trabalhar". (TRIPP, pág. 448) A pesquisa-ação é um tipo de pesquisa social com base empírica que é concebida e realizada em estreita associação de ações, proposições e resoluções de problemas coletivos pautados no contexto social pesquisado. Assim, a pesquisa-ação pré-supõe uma metodologia entendida em um conjunto de procedimentos teórico-práticos ativados na abordagem da realidade. Este estudo adota uma abordagem qualitativa, que permite aprofundamento em uma análise efetuada de forma contextualizada. Entende-se que a investigação pressupõe uma rede de reflexões baseadas em três eixos norteadores ou categorias: A IMAGEM DA MODA, ARTES VISUAIS E EDUCAÇÃO.

A imagem da moda gera tessituras em torno de critérios, definindo atributos a um determinado conjunto de proposições sistematizadas ao redor de um dado objeto configurado como epistemológico. Desta forma, consolida um campo de saber interdisciplinar. É efetivamente um fenômeno da sociedade pós-moderna, associada aos valores e formas de socialização, própria deste tipo de organização social. Talvez seja porque a moda tornou-se este tal objeto reflexivo e comunicativo, que possa ser, seja tratada e pensada como linguagem, possível de ser incluída, ou articulada como fio condutor ao conteúdo mediado nos processos de ensino e aprendizagem em arte. 
Despertar um olhar reflexivo e crítico que permita uma educação para a compreensão tem em uma de suas principais articulações a preocupação com a realidade pessoal, social e cultural onde o sujeito se insere. Isto pressupõe significação entre conteúdo e indivíduo. Assim, o estudo da imagem de moda abordado como fenômeno cultural, pode inferir estratégias didáticas para a compreensão crítica de arte. Desta forma, considera-se 0 caráter interdisciplinar e transdisciplinar da compreensão crítica da Arte. Conforme este pensamento, Franz (2003) configurou um instrumento de avaliação da educação para a compreensão crítica que diz respeito à análise do objeto artístico. Os instrumentos de análise dividem-se em âmbitos de compreensão que são: histórico/antropológico, estético/artístico, pedagógico, biográfico e crítico/social. $\mathrm{O}$ qual se pretende ser pautado como referência da pesquisa, embasando a ação investigativa.

A compreensão de significado histórico/antropológico faz referência a imagens que são frutos de determinados contextos que a produziram e a legitimaram. Para compreender criticamente tal forma de texto visual é necessário ir além do que se vê aparentemente, nessa relação ficam explicados os pontos de conexão entre os significados da imagem e sua tradição: valores, costumes, crenças, idéias políticas e religiosas que a circulam. A compreensão do significado estético/artístico propõe referência à compreensão da arte como produto de sistemas e representações instituídas e legitimadas por determinados valores estéticos de referentes grupos sociais. Neste âmbito, explora-se a percepção e a interpretação crítica do objeto/imagem em paralelismo ao objeto artístico, seguindo o paradigma sociocultural de que obras de arte devem ser vistas em relação à cultura artística e estética do contexto de origem.

A compreensão do significado pedagógico, segundo Franz (2003) se relaciona com a pedagogia de Freire (1999) e Giroux (1998), onde um objeto/imagem deve ser estudado através de uma pedagogia problematizadora e crítica, gerando questionamentos exclusivos ao professor/pesquisador. A compreensão do significado biográfico pode ser possibilitada a partir da valorização pessoal, da produção artística considerada como um impacto na construção da identidade, devendo haver uma contextualização partindo da 
imagem, de modo que o sujeito identifique seu próprio contexto, possibilitando a reflexão crítica de um sistema sociocultural.

A compreensão do significado crítico/social define-se a partir de perguntas que levam em conta a relação entre poder e saber, partindo de uma crítica cultural contemporânea na educação, compreendida como prática de representação do conhecimento construído socialmente de forma subjetiva.

Acredita-se que a moda não deve mais ser vista como um "objeto" de banalidade, pois na contemporaneidade a MODA torna-se um objeto/conceito problematizador de tudo e de todos. Passando pela forma que vemos a estética do cotidiano, o modo como nos vestimos todos os dias, à forma como é considerado o conceito "do corpo" na sociedade; lembrando ainda, campanhas publicitárias, imagens de propagandas que literalmente nos atropelam todos os dias. Percebe-se que em nossa sociedade, mais se vê a forma do que o conteúdo das imagens que nos circulam.

Penso que a imagem da moda, articulada com o viés dos estudos culturais (passando pelos conceitos de cultura, identidade, diferença e representação social), pode ser um caminho para que o professor "olhe" para o contexto do aluno de forma investigativa e reflexiva. Ao abordar a temática da moda, relacionada coma a sociedade, o professor de Artes Visuais terá um fio condutor para trabalhar o conteúdo de Artes Visuais significativamente. A moda é um pré-texto para trabalhar o conteúdo de Artes Visuais na escola. Não se trata de equiparar o sistema estético da moda com a Arte, mas sim buscar uma alternativa de reflexões para a Arte na Educação.

E o que se busca no Ensino da Arte? Articulações que construam conhecimento crítico e reflexivo para o aluno na escola.

Seguindo o pensamento de Araño (2005), pode-se perceber a Arte em um sentido educativo, como uma atividade humana consistente em que o indivíduo se manifesta plenamente capaz de intervir e observar seu contexto. Assim, o significado do termo cultura está submetido a um continuo debate que implica uma realidade muito mais ampla do que a relacionada ao patrimônio artístico. Cultura (conforme GEERTZ, 1990), não é uma realidade, ou algo que se pode atribuir de maneira casual acontecimentos sociais, modos de conduta, instituições ou processos sociais. Compreender a cultura supõe captar seu caráter normal sem reduzir suas particularidades. Assim, a cultura consiste em 
estruturas de significados em virtudes das quais os homens dão forma a sua experiência.

\section{Referências Bibliográficas:}

ARAÑO, Juan Carlos. Estructura del conocimiento artístico In: VIADEL, Ricardo Marín (org). Investigacion en educacion artística. Granada: Universidad de Granada, 2005. BREA, José Luis (org). Estudios Visuales - epistemologia de la visualidad en la era de la globalizacion. Madrid: Ediciones Akal, 2007.

DEBORD, Guy. A sociedade do espetáculo. Rio de Janeiro: Contraponto, 1997. DUNCUM, P. Clarifying visual culture art education. Art Education, 2002a, v.55, n.3, págs. 6-11.

Visual culture art education: why, what and how. Journal of Art \& Design Education, 2002b, v.21, n.1, págs. 14-24.

GAROIAN, Charles R; GAUDELIUS, Yvonne. Spetactacle pedagogy art, politics and visual culture. Pennsylvania: Penn State University, 2008.

GERRTZ, Clifford. La interpretacion de las culturas. Barcelona: Gedisa, 1990.

FRANZ, Teresinha Sueli. Educação para compreensão crítica da arte. Florianópolis: Letras Contemporâneas, 2003.

FREEDMAN, kerry. Enseñar la cultura visual - curriculum, estática y la vida social del arte. Barcelona: Editora Octaedro, 2006.

LAMPERT, Jociele. A imagem da moda muito além da sociedade do espetáculo: proposições para a formação do professor em Artes Visuais In: OLIVEIRA, Marilda de (org). Artes, educação e cultura. Santa Maria - RS: Editora da UFSM, 2007.

MARTINS, Raimundo. A cultura visual e a construção social da arte, a imagem e das práticas do ver In: OLIVEIRA, Marilda de (org). Artes, educação e cultura. Santa Maria - RS: Editora da UFSM, 2007.

MITCHELL, W.J.T. Picture theory. Chicago: University of Chicago, 1995.

MIRZOEFF, Nicholas. Una introduction a cultura visual. Buenos Aires: Paidós, 1998.

SILVA, Juremir Machado. Depois do espetáculo - reflexões sobre a tese 4 de Guy Debord Disponível em: www.compos.org.br. Acessado em : janeiro de 2008.

THIOLLENT, Michel. Metodologia da pesquisa-ação. São Paulo: Cortez, 2004.

TRIPP, David. Pesquisa-ação: uma introdução In: Educação e Pesquisa. V.31, n. 3, São

Paulo: FEUSP, 2005. 